\title{
Tycho Brahe's Critique of Copernicus and the Copernican System
}

\section{Citation}

Blair, Ann. 1990. Tycho Brahe's critique of Copernicus and the Copernican system. Journal of the History of Ideas 51(3): 355-377.

\section{Published Version}

http://dx.doi.org/10.2307/2709620

\section{Permanent link}

http://nrs.harvard.edu/urn-3:HUL.InstRepos:3373453

\section{Terms of Use}

This article was downloaded from Harvard University's DASH repository, and is made available under the terms and conditions applicable to Other Posted Material, as set forth at http:// nrs.harvard.edu/urn-3:HUL.InstRepos:dash.current.terms-of-use\#LAA

\section{Share Your Story}

The Harvard community has made this article openly available.

Please share how this access benefits you. Submit a story.

\section{Accessibility}




\section{Tycho Brahe's Critique of Copernicus and the Copernican System}

Ann Blair

For Luther he was the "fool who wanted to turn the art of astronomy on its head"'; for François Viète he was the paraphraser of Ptolemy and "more a master of the dice than of the (mathematical) profession"; for nearly every intellectual in the century following De revolutionibus Copernicus was a figure to be evaluated and criticized, if not always understood. Tycho Brahe's critique of Copernicus is not summed up in any pithy statement but rather spread throughout his life's work. Yet it reveals the constant importance of Copernicus and his shortcomings as the point of departure for Tycho's own model and observations.

Tycho Brahe (1546-1601) was not unusual in combining a certain admiration for Copernicus with a consistent rejection of heliocentrism. Beyond the rather commonplace criticisms of the Copernican system based on physical, scriptural, and cosmological arguments, Tycho's published works and astronomical correspondence reveal countless attempts to disprove or discredit the Copernican hypothesis on empirical grounds. This criticism of Copernicus's parameters and observational practice, although less well known, ${ }^{3}$ is an integral part of, perhaps even a source for, Tycho's influential new agenda of "restoring" astronomy through greater

I would like to thank Noel Swerdlow, Anthony Grafton, Michael Mahoney, and Jean Céard for helpful comments.

1 "Der Narr will die ganze Kunst Astronomiae umkehren." Martin Luther, Tischreden IV, no. 4630 (Weimar, 1916), as quoted in Noel Swerdlow and Otto Neugebauer, Mathematical Astronomy in Copernicus' De Revolutionibus (2 vols.; New York, 1984), I, 3.

${ }^{2}$ François Viète, "Apollonius Gallus" (Paris, 1600) in Opera mathematica, 343, as quoted in Otto Neugebauer, "On the Planetary Theory of Copernicus," Astronomy and History: Selected Essays (New York, 1983), 491-505.

${ }^{3}$ Reference is made to certain of these arguments in Christine Schofield, Tychonic and Semi-Tychonic World Systems (New York, 1981), 37-39, and in Kristian Peder Moesgaard, “Copernican Influence on Tycho Brahe," Studia Copernicana, V (Warsaw, 1973), 31-56.

Copyright 1990 by Journal of The History of IdeAs, Inc. 
observational accuracy and a more directly empirical derivation of planetary models.

\section{The development of Tycho's agenda}

In his first public reference to Copernicus, when lecturing on mathematics for a few months in 1574 at the University of Copenhagen, Tycho formulated what would remain his basic attitude toward the Copernican system. He hailed Copernicus as a second Ptolemy, praising him for avoiding the mathematical absurdity of the equant point and for "philosophizing more exactly than anyone before him" about the course of the stars. At the same time he criticized the heliocentric hypothesis for its features that were "opposed to physical principles," the motion of the earth and immobility of the sun and of the sphere of the fixed stars. ${ }^{4}$ Tycho then promised that while abiding by the spirit and numbers (mentem et numeros) of Copernicus, he would reestablish the stability of the earth and show "how the appearances of the other planets could be adapted to the stability of the earth, while the Copernican numbers stayed the same, and how this could be done differently from Peucer and Dasypodius" (I, 173). Although Tycho clearly expressed praise for Copernicus's work and even a preference for the physical absurdities of heliocentrism over the "mathematical" absurdity of non-uniform circular motion in the Ptolemaic system, ${ }^{5}$ he never doubted that Copernicus's hypothesis was flawed.

Throughout his writings Tycho would continue to display great admiration for Copernicus, whom he usually called ingens or incomparabilis (VI, 102; VII, 199, for example), citing above all his ingenuity and mathematical talent. Tycho devoted a prominent portion of his book of published astronomical letters to a fulsome description, complete with poetic elegies of his own composition, of the mementos of Copernicus and other great astronomers which surrounded him in his workplace at Uraniborg. On his wall Tycho kept portraits of Timocharis, Hipparchus, Ptolemy, alBitruji, Alphonso X, and Copernicus, alongside those of himself and his young son Tychonides, whom he included in the pantheon in anticipation of great work to come. Of Copernicus in particular Tycho cherished the parallactic instrument which an assistant had brought back from an observing expedition to Frauenburg and which was displayed at Uraniborg, accompanied by a special ode. Once included amid the great astronomers of all time, however, Copernicus was not only owed deep respect,

${ }^{4}$ Tycho Brahe, "De disciplinis mathematicis oratio" (1574), J. L. E. Dreyer (ed.), Opera omnia (14 vols.; Copenhagen, 1913-29), I, 149. Further references to the Opera omnia will be made by volume and page number in parentheses; all translations are my own.

${ }^{5}$ Tycho would continue to perceive Copernicus's motion of the earth as a lesser evil than Ptolemy's use of the equant point, as he does for example in a letter to Christoph Rothmann dated 1587 (VI, 102). 
but was also open to that reverent yet critical examination characteristic of Copernicus's own treatment of Ptolemy or of Vesalius's attitude toward Galen.

As early as 1574 Tycho expressed his enthusiasm for what Copernicus had "restored" in astronomy only alongside his own call for astronomy to be further "restored," first by reestablishing the stability of the earth and later by improving through better observation the hypotheses of planetary motion. It is precisely to this "restoration" (redintegratio or restitutio) that Tycho devoted the rest of his life and writings. The concept was not peculiar to Tycho but appeared in the writings of many contemporaries $^{6}$ and can be recognized for example in Copernicus's preface to $D e$ revolutionibus, in which he deplores the jumbled and monstrous state of astronomy. ${ }^{7}$ Rather than a return to any particular cosmological system or set of parameters, the term referred more loosely to an unspecified ideal astronomy from a mythical past, perfect in all respects. But while all sixteenth-century astronomers agreed that astronomy had to be restored, they differed on exactly which aspects of astronomy required most attention. Tycho expressed his personal goal in a letter to Rothmann in August 1588: "I will endeavor to adapt my restorations [restitutiones] in the course of all the planets to my own hypothesis, not one already invented, and to show the agreement of computation with them and with the heavens themselves, and I have decided therefore to set them out in a special work, God willing" (VI, 147).

Tycho's agenda at its maturity was thus two-fold, to find a new hypothesis, in particular one that avoided the absurdities of both the Ptolemaic and the Copernican systems, and to establish through observations its agreement with the heavens themselves rather than with any given parameters. While Tycho's lectures of 1574 already outlined the first part of this project, to reestablish the stability of the earth to the otherwise admirable Copernican system, they did not yet involve much criticism, like that implicit in the letter to Rothmann and explicit in so many other instances after 1578, of Copernicus's observations or parameters. As Tycho recounts in his work on the comet of 1577 , De mundi aetherei recentioribus phaenomenis liber secundus, ${ }^{8}$ it was only in attempting to trace the course of the

\footnotetext{
${ }^{6}$ Charles Whitney suggests that Tycho's use of the related concept of an "instaurata astronomia" (renovated astronomy) was influential in Bacon's choice of title for his Instauratio magna ("Francis Bacon's instauratio: Dominion of and over Humanity," JHI, 50 [1989], 371).

${ }^{7}$ Nicolas Copernicus, De revolutionibus orbium coelestium, facsimile reprint of 1543 edition (New York and London, 1965), f. iij v.

${ }^{8}$ Brahe, De mundi aetherei recentioribus phaenomenis liber secundus qui est de illustri stella caudata ab elapso fere triente Novembris Anni 1577, usque in finem Ianuarij sequentis conspecta (Uraniborg, 1588), reprinted in Opera omnia, IV, also available in translation: Sur des phénomènes plus récents du monde éthéré, tr. Jean Peyroux (Paris, 1984). The work was already at least partially composed by 1578 (Schofield, 52).
} 
comet that he first began to check Copernicus's parameters and to find them wanting.

Tycho found that the positions of the stars in relation to which he would chart the comet's path corresponded neither to Ptolemy's nor to Copernicus's computations. Both had relied, Tycho concluded, on the tables of latitudes and longitudes established by Hipparchus and Ptolemy which involved errors of one degree or more. ${ }^{9}$ Tycho attributed these errors to "the carelessness (incuria) either of the observers or of the transcribers or rather of both" (IV, 20). Before he could calculate the successive positions of the comet, Tycho's first task was to "restore to pristine condition" (in integrum restituere), from his own observations, the positions of all the stars he would use as points of reference. Tycho devoted the second chapter of De mundi recentioribus phenomenis to his results, and thus initiated the second part of his "restoration" project which would before long grow to include new and more reliable observations for virtually all the celestial bodies.

Whereas in 1574 Tycho had been content to accept Copernicus's "numbers," by 1578 he realized that he could no longer rely on them. Spurred from then on by his dissatisfaction with both the parameters and the hypotheses of Copernicus, Tycho strove toward a model which would satisfy the requirements of mathematics, physics, and his own more accurate observations. By the mid-1580s Tycho had settled on his geoheliocentric model, first outlined in print in $1588 .{ }^{10} \mathrm{He}$ offered it as the perfect compromise between the Scylla of Ptolemy and the Charybdis of Copernicus (IV, 473-74), combining what he admired in both systems while avoiding the absurdities of each. Meanwhile Tycho continued his exacting restoration of the motions of the celestial bodies throughout his life, and would use his numerous corrections to claim, with rhetorical rather than logical force, that his system alone could account exactly for the phenomena.

Tycho never presented his system in final and fully argued form as he had hoped to some day in a Theatrum astronomicum, ${ }^{11}$ but his massive astronomical correspondence, available in three volumes of the Opera omnia, offers a wealth of detail and debate from which to follow his argument. The letters are dated between 1571 and a few months before his death in 1601, but most were written after the mid-1580s, once he had developed his own cosmological system and was comfortably installed with his observatories and assistants on the island of Hveen. ${ }^{12}$ In keeping

${ }^{9}$ For Tycho's judgment of their relative merits, see below p. 18.

${ }^{10}$ De mundi aetherei recentioribus phaenomenis liber secundus, ch. 8.

${ }^{11}$ Moesgaard, 40.

${ }^{12}$ The main building of Tycho's estate, the Uraniborg proper, served as both dwelling and workplace and was completed in 1580 . It included a large library containing major instruments like the mural quadrant in use from 1582, and two small observatories. A separate observatory, the Stjerneborg, was built, largely beneath ground for protection from the wind, in 1584. Tycho first set up his own printing press in the same year. Tycho's first assistant arrived in 1578, then Paul Wittich in 1580; Gellius, Olsen, and 
with the habits of late humanist scholars, Tycho corresponded with serious astronomers throughout Europe employed in a variety of occupations. ${ }^{13}$ These ranged from university professors of mathematics and/or medicine to the physicians and astronomers attached to imperial or princely courts, to officials and rulers in the Holy Roman Empire, who often cultivated a personal interest in astronomy and measurement. ${ }^{14}$ Of the professors, some he had known while a student, like Caspar Peucer at Wittenberg and Henry Brucaeus at Rostock, others he knew only through letters and intermediaries, like Giovanni Antonio Magini at the University of Bologna or Joseph Justus Scaliger at Leiden. Tycho carried on lively exchanges from Hveen with Thaddeus Hagecius, physician to the emperor in Bohemia and, after leaving Denmark in 1597, with his assistant Johannes Kepler, and with Herwart von Hohenburg, chancellor of Bavaria, among others. Most importantly Brahe corresponded regularly between 1586 and 1591 with Wilhelm IV, Landgrave of Hesse, whose observatory at Kassel was a major center of astronomical activity, and with his court astronomer, Christoph Rothmann, a convinced Copernican. Tycho published these letters to Kassel in 1596 as his Epistolarum astronomicarum liber primus ${ }^{15}$ but never carried out plans for publishing more of his correspondence.

\section{Tycho's assessment of heliocentrism}

In an important letter of 1588 to Caspar Peucer, Tycho presented most completely his perception of the shortcomings of Ptolemy which Copernicus had resolved:

[In examining the Ptolemaic hypotheses] I noticed ... that although they save to a great extent the heavenly appearances, because however they allow that the motion of a circle be regular not around its own center, but around some other point, they sin against the first principles of the art, which Copernicus himself seems to have criticized in these hypotheses; furthermore the great number and great size of the epicycles that are assumed take up much space in the sky and are superfluous. I considered whether everything could be resolved by fewer [of them], and it gave me great concern that no necessary cause or natural combina-

Longomontanus are the better known of the pupils who worked at Hveen during the 1580s and 1590s. J. L. E. Dreyer, Tycho Brahe: A Picture of Scientific Life and Work in the Sixteenth Century (New York, 1963), 94-104, 115-27.

${ }^{13}$ On the emergence of a status of "scholar" see Erich Trunz, "Der deutsche Späthumanismus um 1600 als Standeskultur," Richard Alewyn (ed.), Deutsche Barockforschung: Dokumentation einer Epoche (Cologne, 1965), 147-81.

${ }^{14}$ See for example Bruce T. Moran, "Princes, Machines and the Valuation of Precision in the Sixteenth Century," Sudhoffs Archiv, 61 (1977), 209-28, and "German PrincePractitioners: Aspects in the Development of Courtly Science, Technology, and Procedures in the Renaissance," Technology and Culture, 22 (1981), 253-74.

${ }^{15}$ Brahe, Epistolarum astronomicarum liber primus (Uraniborg, 1596), reprinted as vol. VI of Dreyer's Opera omnia. 
tion explained why the superior planets are bound to the sun in such a way that at conjunction they always occupy the top of their epicycles, at opposition the lowest point of the same, and that the two planets that are called inferior always have the same mean position with the sun and are close to it at the apogee and perigee of their epicycles. (VII, 128)

Tycho admires the Copernican system because he finds it far more elegant than the Ptolemaic (longe concinnior, VII, 80). And, without considering for the moment the triple motion of the earth, Tycho finds that Copernicus "resolves well all the other aspects of the Ptolemaic arrangement which are confused and superfluous, and in no way sins against the principles of mathematics" (VII, 128).

This appraisal of the advantages of the Copernican system was fairly common in the sixteenth century even among those who, like Tycho, rejected heliocentrism because of the motion of the earth. Although widespread, it was not particularly accurate, however, as Copernicus's completed model used no fewer circles than Ptolemy's. But in the skeleton of the Copernican model at least, the epicycle that Ptolemy had attributed to each individual planet could be accounted for by the single annual rotation of the earth. It is no doubt this conceptual simplicity which appealed to Tycho and many contemporaries. Indeed Tycho probably rejected the Ptolemaic system in the first place and devised a system of his own precisely in order to preserve the explanatory power he found so attractive in Copernicus's heliocentrism. In the Tychonic system the motion of the planets around the sun, while the sun revolved around the earth, still accounted for the stations and retrogradations of the planets which had required the epicycles in the Ptolemaic model. But when Tycho actually adjusted his theory to fit the parameters derived from his observations, as he did in the case of the moon for example, he too in the end had only added further epicycles to the existing models.

In many instances, starting with his 1574 lecture, Tycho praised Copernicus for avoiding Ptolemy's "sin" against the "first" or the "mathematical" principles of the art. Like many before him, including Copernicus, Tycho objected here to Ptolemy's explicit use of non-uniform circular motion and what was later called the equant point - a point around which the epicycle of a planet maintains a constant angular velocity even while it follows a path centered on a different point. But Copernicus no less than Ptolemy needed the planets in his model to move in a non-uniform circular motion, in order to approximate, quite successfully in fact, Ptolemy's own model. He did so more subtly than Ptolemy, however, through a combination of eccentric circles and epicycles, which yielded almost the same result as the problematic circle revolving around a point other than its center.

The equivalence of Copernicus's eccentrepicyclic model to Ptolemy's equant point was not lost on some students of Copernicus, such as Michael 
Maestlin and Kepler, who corresponded on the subject. ${ }^{16}$ Tycho, however, never alluded to the problem in Copernicus and on the contrary praised the latter precisely for avoiding the mathematical absurdities of the Ptolemaic system. He seemed satisfied with Copernicus's more discreet model for producing non-uniform circular motion and in any case had no alternative to offer. Tycho focused rather on those problems in the Copernican system which he felt he could resolve.

Tycho's main objection to the Copernican system, and one that geoheliocentrism avoided, concerned the motion of the earth. Tycho shows no sign of having speculated, as Copernicus did in De Revolutionibus book I, about alternatives to Aristotelian physics that could accommodate a moving earth. The annotations in Tycho's copy of the De Revolutionibus, once taken as evidence for such speculation, have now been identified as those of Paul Wittich. ${ }^{17}$ Already in 1574 Tycho made it clear that the motion of the earth violated "physical principles" and could not be tolerated. In 1584, in a letter to his friend Henry Brucaeus, professor of medicine and mathematics at Rostock, Tycho expressed a rare moment of doubt. Of the three motions Copernicus had assigned to the earth, Tycho believed that he had disproved the annual motion by his measurement of the parallax of Mars at opposition and had dismissed Copernicus's libration of the earth, added to account for the precession of the equinoxes, as both unnecessary and in any case based on inaccurate observations. As for the third, daily rotation of the earth, Tycho briefly wondered:

But whether this third motion, that accounts for the daily revolution, belongs to the earth and nearby elements, is hard to say. For with the same reason the appearance of so great a motion can be explained in the earth and in the primum mobile [the outermost sphere] and the sudden return from East to West of all the spheres in the second mover [beneath the fixed stars] can be saved with a much smaller revolution, and therefore a more convenient short-cut, as I see that the Pythagoreans and Platonists believed. (VII, 80)

This was the extent of Tycho's consideration, however, as he immediately concluded: "It is likely nonetheless that such a fast motion could not belong to the earth, a body very heavy and dense and opaque, but rather belongs to the sky itself whose form and subtle and constant matter are better suited to a perpetual motion, however fast" (VII, 80). ${ }^{18}$ On other occasions Tycho dismissed the motion of the earth as useless (irritus, VI, 27) and an absurdity (VI, 177; VII, 199).

${ }^{16}$ Anthony Grafton, "Michael Maestlin's Account of Copernican Planetary Theory," Proceedings of the American Philosophical Society, 117 (1973), 523-50.

${ }^{17}$ Owen Gingerich and Robert S. Westman, The Wittich Connection: Conflict and Priority in Late Sixteenth-Century Cosmology, Transactions of the American Philosophical Society, vol. 78, part 7 (Philadelphia, 1988), 23.

${ }^{18}$ For a similar discussion of the possibility of daily rotation see Tycho's letter to Kepler in 1598 (VIII, 45). 
Tycho's rejection of the motion of the earth rested at times on Aristotelian physics and his conviction that the earth is a "lazy and ignoble" body (piger et ignobilior, VII, 128) whose nature does not lend itself to motion, unlike the ethereal substance of the heavenly bodies for whom motion, "however fast," is natural. At other times Tycho reasoned from common sense, adducing in his responses to Christoph Rothmann arguments made famous by Galileo's dialogues: that if the earth were turning, a canon-ball fired in the direction of the motion of the earth would travel farther than one fired in the opposite direction (VI, 219), or that a lead ball dropped from a tower would fall beyond the bottom of the tower (VI, 197). Neither was original with Tycho, who could have read them in the writings of Caspar Peucer, for example. ${ }^{19}$

In summarizing his reasoning for Peucer, Tycho also reveals the importance of "the unquestionable authority of the holy scriptures," which he cites as the second "obstacle to the regular and perpetual revolution of the earth" (VII, 129). ${ }^{20}$ Although Tycho rarely used this argument in isolation, he did take it seriously, and contrasted the clear position of the Bible on the motion of the earth with its silence concerning the reality of celestial spheres. In the wake of the comet of 1577 Tycho had taken the novel position that the orbs carrying the planets had no real existence and was thus particularly interested in anticipating possible objections to his views based on the Bible. As Christine Schofield points out, ${ }^{21}$ Tycho concluded in his Astronomiae instauratae progymnasmata, ${ }^{22}$ that "neither scripture nor true philosophy will prove that the heavens have solid orbs" (III, 151). He based this conclusion not on the weakness of the authority of scripture, but rather on the ambiguity of the authoritative texts, for while some passages in the Bible seem to imply solid orbs, "there are many other places in the holy scripture to the contrary which show that the sky is something very liquid and very fine" (III, 151). Tycho even made the further claim that "the very liquid and permeable substance of the heavenly world can be proved from the sacred writings" (VI, 187). ${ }^{23}$

In his debate with Rothmann on the motion of the earth, however, Tycho found the Bible both literally authoritative and unambiguous. Rothmann argued, much as Galileo would later in his "Letter to the Grand Duchess Christina," that the biblical texts that seemed to deny the motion of the earth were written to accommodate the understanding of the common man and could not constitute an objection to the Copernican

${ }^{19}$ Schofield, 92.

${ }^{20}$ See also III, 175; VII, 199.

${ }^{21}$ Schofield, 90.

${ }^{22}$ Brahe, Astronomiae instauratae progymnasmata quorum haec prima pars de restitutione motuum solis et lunae stellarumque inerrantium tractat et praeterea de admiranda nova stella Anno 1572 exorta luculenter agit (Prague, 1602), reprinted in Opera omnia, II and III. The printing was begun at Uraniborg in 1588 .

${ }^{23}$ See also IV, 474. 
system, about which "we will know only as much as we find through mathematical demonstrations" (VI, 160). Far from being convinced, Tycho responded so forcefully that in his next letter he had to reassure Rothmann that he had not meant to accuse him of impiety, adding: "I do not take it upon myself to judge anyone's piety or impiety" (VI, 185).

Tycho refused to allow that the prophets, even while addressing the crowds, might have spoken untruths. "The authority and reverence of the divine scriptures is and must be greater than as if it were appropriate to treat them in the manner of a play script. Granted that in physics and some other fields they adjust themselves very well to the level of the crowd, nonetheless far be it from us to decide that they speak in so vulgar a way that they do not also seem to set out truths" (VI, 177). In using a theory of accommodation to dismiss certain of their statements, Rothmann "detracts too much from the prophets by saying that they did not understand more about the nature of things than other vulgar men. Although they did not treat of physics by profession, indeed this was not the nature of their gift, nonetheless they mixed many physical propositions in with their prophecies, which no one, however deeply imbued in natural philosophy, could deny" (VI, 177-78).

Instead of interpreting the Bible "more freely" as Rothmann proposes, citing Augustine as an example (VI, 181), Tycho praises contemporaries who study the physics contained in the scriptures. Francisco Valles, for example, "explained many things which must not be neglected among the matters of physics contained in the scriptures" and Lambert Daneau is hailed as "a very erudite man and one who has done excellent service in educating others" for his "theological physics" drawn from the old and new testaments. ${ }^{24}$ Tycho concludes: "It is possible that many things lurk here that should be explained differently, to follow a better system of physics-which is itself, perhaps, to be found to a considerable extent in scripture" (VI, 185).

Tycho's parting challenge to Rothmann to "cite any text you have from the holy oracles or their commentators that supports the Copernican assertion" (VI, 186) is, on the one hand, a rhetorical ploy; indeed Tycho adds immediately: "I know this well enough that Augustine, the only one you name, never conceded the annual or diurnal motion of the earth; not being much of a mathematician, he questioned the very roundness of the earth by denying the antipodes" (VI, 186). But on the other hand it also grows out of his conviction that many truths of physics are contained in the holy scriptures. If Tycho left to others the practice of a scriptural physics, he remained deeply committed to the physical truth of those

${ }^{24}$ Tycho is referring here to their recent works: Franciscus Valles, De iis quae scripta sunt physice in libris sacris, sive de Sacra Philosophia liber singularis (Lyon, 1588), and Lambert Daneau, Physica Christiana, sive de Rerum creatarum cognitione et usu, disputatio e Sacrae Scripturae fontibus hausta et decerpta (Geneva, 1576). 
biblical statements which entailed the stability of the earth. After this heated exchange with Rothmann, however, Tycho rarely discussed the issue, but focused instead on astronomical arguments against Copernicus.

In the absence of any observed stellar parallax, Tycho scoffed for example at the absurdity of the distance and the sizes of the fixed stars that the Copernican system required:

Then the stars of the third magnitude which are one minute in diameter will necessarily be equal to the entire annual orb [of the earth], that is, they would comprise in their diameter 2284 semidiameters of the earth. They will be distant by about 7850000 of the same semidiameters. What will we say of the stars of first magnitude, of which some reach two, some almost three minutes of visible diameter? and what if, in addition, the eighth sphere were removed higher, so that the annual motion of the earth vanished entirely [and was no longer perceptible] from there? Deduce these things geometrically if you like, and you will see how many absurdities (not to mention others) accompany this assumption [of the motion of the earth] by inference. (VI, 197)

Tycho also shared this misgiving with a number of contemporaries. He himself had searched repeatedly for any sign of a parallax in the sphere of the fixed stars, but to no avail (VIII, 209). The consequences, then, were simply too monstrous to be believable. Tycho stressed his conviction on this point in the Progymnasmata: "It is necessary to preserve in these matters some decent proportion, lest things reach out to infinity and the just symmetry of creatures and visible things concerning size and distance be abandoned: it is necessary to preserve this symmetry because God, the author of the universe, loves appropriate order, not confusion and disorder" (II, 435).

There is nothing particularly unusual in Tycho's use of these three arguments against the Copernican system. The physical absurdity of the motion of the earth, confirmed by the enormous distance to the fixed stars and evidence from the Bible, sealed Tycho's rejection of heliocentrism. Schofield also suggests that Tycho's dissatisfaction with Copernican parameters contributed to his "loss of confidence" in the new system; ${ }^{25}$ but from the chronology of Tycho's development it is clear that Tycho rejected the motion of the earth already in 1574 , well before he had begun seriously to investigate the accuracy of Copernicus's numbers. Once he had started his vast observational project, however, Tycho discovered a whole new range of arguments with which to undermine the Copernican system.

\section{Two empirical "proofs"}

The first of Tycho's empirical arguments, from the observation of the parallax of Mars, might have been quite convincing had he been able to

${ }^{25}$ Schofield, 38. 
sustain it. In his letter to Brucaeus of 1584 Tycho recounted how he had devised a simple empirical test of the Copernican system. In the Ptolemaic system Mars is always further away from the earth than the sun. The Copernican model, however, places Mars at opposition closer to the earth than the sun is to the earth. Therefore a simple comparison of the parallaxes of the sun and of Mars at opposition should determine conclusively which of the two systems is true, a smaller parallax of Mars disproving the Copernican system. Tycho reported that at the end of 1582 and especially in 1583, "by most frequent and precise observations," he had found that the parallax of Mars was much smaller than that required by Copernicus; he concluded that "the whole sphere of Mars is further removed from us than the sun" and "the annual motion of the earth in a great circle around the sun does not exist" (VII, 80). Tycho had not redetermined the solar parallax for this test, but used throughout his writings the Ptolemaic value of approximately 2'50", while the solar parallax actually does not exceed 9 seconds. ${ }^{26}$ Given the value he assumed for the solar parallax, his observation of a smaller parallax of Mars is perhaps not surprising.

What is startling, however, is the further development of Tycho's account of the parallax of Mars. In his letter of 1588 to Caspar Peucer, Tycho's description of the parallax test based on those same observations of 1582-83 and on the same value for the solar parallax, had changed drastically:

And finally with great diligence and at no small cost using various astronomical instruments by which the movements of the heavenly bodies can be measured accurately not only to the minute, but even to the half or quarter of a minute of arc, and having taken many such accurate observations at the rising, setting and meridian transit of Mars, I found that Mars displays a greater parallax than the sun and is therefore closer to the earth than the sun when it is in opposition, which is in agreement with the Copernican numbers. (VII, 129; my emphasis)

This reversal has puzzled many commentators, starting with Kepler, who tried to justify it by attributing it to the error of Tycho's assistants, who had misunderstood their instructions. ${ }^{27}$ As J. L. E. Dreyer points out, however, Tycho's notes on the observation and the parallax calcula-

${ }^{26}$ J. L. E. Dreyer, "Note on Tycho Brahe's Opinion About the Solar Parallax," Monthly Notices of the Royal Astronomical Society, 71 (1910), 74-76. As Schofield points out (p. 70), in the Progymnasmata Tycho endorsed the number mysticism of Johannes Francus Offusius who set the earth-sun distance at 576 earth diameters, the square of 24 (II, 421-22).

${ }^{27}$ Johannes Kepler, Astronomia nova seu Physica coelestis, tradita commentariis de motibus stellae Martis (Prague, 1609), Gesammelte Werke, Max Caspar (ed.) (18 vols.; Munich, 1937-59), III, 121, 461-62. 
tion were taken in his own hand (X, 196ff. and $283 \mathrm{ff}$.). ${ }^{28}$ Schofield suggests that Tycho's later version of the test was due to his faulty recollection of what had impressed him about Copernicus's model for Mars: when he found that the positions of Mars corresponded better to the Copernican than to the Ptolemaic model, Tycho erroneously assumed that the parallax he had observed earlier also supported Copernicus over Ptolemy. ${ }^{29}$ On this interpretation Tycho would have rather surprisingly confused a weak argument from the agreement of parameters with a much stronger kind of empirical test.

Whatever the observational basis for the two versions of the story, ${ }^{30}$ the shift cannot be understood without reference to the development of Tycho's cosmological commitments. In the early 1580 s Tycho was simply opposed to heliocentrism and used his observation of the parallax of Mars as one of his strongest arguments against the Copernican system. But by 1588 Tycho had also settled on an alternative to heliocentrism in his geoheliocentric model, which, like the Copernican system, placed Mars closer to the earth than the sun at opposition. This arrangement, with its overlapping spheres of Mars and the sun, was possible only after Tycho had abandoned his belief in the solidity of the celestial spheres. Tycho was thus forced to abandon his first account of the parallax of Mars, as it would infirm not only the Copernican but also his own cosmological model, to which he was deeply attached.

So if Tycho's second and final account of his observation of the parallax of Mars $^{31}$ supported his own system, by the same token it involved abandoning one of his strongest arguments against Copernicus. In order to maintain the symmetry of his carefully constructed letter to Peucer, Tycho used his discussion of the parallax of Mars to refute the Ptolemaic system and offered another refutation of the Copernican system instead. Comets, Tycho pointed out, do not display retrograde motion. As he explained in the De mundi aetherei phaenomenis however, they behave like planets in many ways. Located in the ethereal region with the planets, comets travel around the sun just beyond the sphere of Venus. Their orbit is freer than the planets' but still roughly similar: "It is probable that comets, since they do not have perfect bodies designed to last forever ... do not observe in their orbits such an absolute and constant continuity and equality, but only like mimes emulate in some way the uniform regularity of the planets, but do not attain it in all things" (IV, 162). Since,

${ }^{28}$ Dreyer, Tychonis Brahe opera omnia, I, xxxix-xl. Dreyer had earlier accepted Kepler's account in Tycho Brahe, 179, but changed his opinion on the basis of Tycho's notebooks. Owen Gingerich, "Dreyer and Tycho's World System," Sky and Telescope, 64 (1982), 138-40.

${ }^{29}$ Schofield, 66-68.

${ }^{30} \mathrm{~A}$ close reading of the notebooks might elucidate this problem.

${ }^{31}$ Tycho repeats the argument to Rothmann (VI, 179) and Hagecius (VII, 199-200) in 1589. 
although planet-like, the comets do not display retrograde motion, Tycho argued that the stations and retrogradations that we see in the motion of the planets must really be theirs rather than due to the motion of the earth as Copernicus claims: "In addition the two comets which were carried near the opposition of the sun showed clearly enough that the earth does not in fact revolve annually, since the motion of the earth did not detract in any way from their regular and established motion, as happens to the planets which Copernicus believes move backward because of the motion of the earth" (VII, 130). In short, if the earth revolved annually around the sun, why would the comets not also display retrograde motion?

Tycho's argument is not entirely consistent: in his system no less than Copernicus's the stations and retrogradations of bodies revolving around the sun are due to the position of the observer on earth, which is either stationary while the sun is not (geoheliocentrism), or in motion while the sun is immobile (heliocentrism). Therefore comets that revolved like the planets around the sun would be expected to display retrograde motion in both systems. Furthermore, even if Tycho did not see this fundamental flaw in his argument, he might have noticed that it affected only the annual, not the daily rotation of the earth. Nevertheless, Tycho clearly believed that his argument from the behavior of comets was forceful. In a letter to Magini, professor of mathematics at Bologna, dated 1590, Tycho described his arguments about comets. The Copernican system, he proclaimed, with its "triple motion of the earth will be unquestionably refuted, not simply theologically and physically, but even mathematically, even though Copernicus hoped that he had proposed to mathematicians sufficiently mathematical statements to which they could not object" (VII, 295). Tycho was especially proud to announce a refutation of Copernicus on his own ground, responding to the latter's remark in the preface to $D e$ revolutionibus that "mathematics is written for mathematicians." 32

\section{The evidence of Copernicus's parameters}

At a loss for other "mathematical" proofs, Tycho most often attacked Copernican parameters and observations. When taken individually, none of the discrepancies he catalogued actually disproved the Copernican system, which could have been modified in each detail as necessary to fit his new data; yet Tycho clearly hoped to discredit heliocentrism by pointing to the unreliability of Copernicus's numbers, as if it logically entailed that the Copernican system could not be sustained.

Tycho never advocated simple empiricism nor claimed a direct derivation of his geoheliocentric model from observations free of "hypotheses." This is clear from his position on the famous call by the contemporary

${ }^{32}$ Copernicus, f. iiij v. In this passage a "mathematical" argument for Tycho seems to be one that depends on the internal consistency of a system. 
French philosopher Peter Ramus for an "astronomy without hypotheses" modelled on the strict empiricism of the Egyptians. In a letter to Rothmann sixteen years later, Tycho reports that in 1571 Ramus had suggested to him over a meal one day in Augsburg that he attempt to constitute an astronomy "through logical reasons without hypotheses." But Tycho "resisted him, showing that without hypotheses the celestial phenomena cannot be reduced to a certain science nor dispensed with so as to be understood" (VI, 88). He concluded that Ramus, although "gifted with a perspicacious intelligence and a lover of truth if any there was, did not seem to have penetrated deeply into this art [of astronomy]" (VI, 88). Hypotheses are necessary because "they show the measure of apparent motion through a circle and other figures which arithmetic solves into numbers" (VI, 89). Although in principle both the Copernican and the Tychonic hypotheses could be modified to accommodate more precise observations, once he had settled on his geoheliocentric system for the reasons outlined above, Tycho used Copernicus's errors in describing the motions of the earth/sun, ${ }^{33}$ moon and planets, the positions of the stars and the precession of the equinoxes as evidence that Copernicus's inadequate standards of observation and derivation could not be trusted to yield a valid cosmological system.

After his first mention of errors in Copernicus's stellar positions in 1577 , which he had meekly attributed to the errors of the ancient observations or of those who transcribed them, Tycho discovered more and more discrepancies between the Copernican parameters and his own observations, which he increasingly blamed on Copernicus himself and his poor observational practice. Copernicus's errors in predicting the course of the sun were the first that Tycho examined closely. In 1580 already, in a letter to the Bohemian physician-astronomer Thaddeus Hagecius, Tycho complained:

The calculations of Alphonso and Copernicus sometimes differ from [my] observations [of the course of the sun] by half of one degree, or at times more... The motion of the center of the sun's eccentric in its epicycle is very different than our predecessors and even Copernicus himself determined, so that the eccentricity of the sun is now $2^{\circ} 5^{\prime}$, that is $13^{\prime}$ greater than what Copernicus thought. The apogee of the sun is near $5^{\circ}$ of Capricorn, much farther ahead of what the hypotheses of Copernicus say. (VII, 60)

In a letter to Rothmann in 1587, Tycho could provide an explanation for these errors. Indeed "the fact that the eccentricity of the sun, its apogee and entire course had come to disagree so enormously from Copernicus's hypotheses in a short number of years" (VI, 103) led him to suspect an

${ }^{33}$ Given his commitment to the immobility of the earth Tycho discusses Copernicus's motion of the earth as the motion of the sun. The two are interchangeable in the geocentric and heliocentric models. 
error in Copernicus's measurement of the polar altitude of Frauenburg. Tycho sent one of his assistants to Copernicus's home in Prussia with a load of precision equipment to measure the elevation with his own instruments. The observations yielded a polar elevation of $54^{\circ} 22^{\prime 1} 1 / 4$ for Frauenburg, a value in excess of Copernicus's by "about three minutes" (VI, 103). Tycho concluded from Copernicus's writings that the latter "had probably not avoided the effects of refraction at his inclined location and perhaps also had not taken parallax into account" (VI, 103). By Tycho's standards, Copernicus had failed to fulfill the responsibilities of the careful observer.

As a mitigating circumstance, Tycho did recognize that Copernicus's tools, such as the parallactic instrument which was brought back for him from Frauenburg, were primitive. Laying out new ground rules for the observational astronomer, Tycho wrote in his Apologetica responsio ad Craigum Scotum (1589):

If you have made your rulers out of wood, you accomplish nothing because they are not well enough suited to fine divisions and are not free from all change; if you have made them of metal, they will not suffice unless they are of the right length and size to allow for the divisions that yield minutes; but when they have the requisite size, their own bulk weighs them down so that when inclined however slightly away from the level of the straight line they cause a loss of the sought-after certainty, as daily experience has taught me. (IV, 464)

Tycho concluded therefore that the "rulers of wood" which Copernicus had made and that were given to him by the canon of Warmia were "totally useless because of the instability of the material" (IV, 464). ${ }^{34}$

In keeping with his aristocratic self-image, ${ }^{35}$ Tycho was proud to point out that the construction of the huge metal instruments he owned required considerable patronage, and he willingly granted in his letter to Peucer that many of his colleagues were not as fortunate as he:

The mathematicians of our age are nevertheless excusable because they do not own large enough and appropriate instruments with which to investigate the motions of the stars, since their salaries and all their yearly revenues would hardly suffice to pay for a single properly built instrument. Indeed I know that I own many instruments each one of which would far surpass in price of construction the annual salary, even the highest, of any university professor. (VII, 139)

Thus Tycho conceded to Rothmann that if Copernicus had had at his disposal the fine-tuned instruments available at Uraniborg, he would have reached far better results (VI, 102).

${ }^{34}$ See the similar discussion in his Astronomiae instauratae mechanica (Wandesburg, 1598), V, 45.

${ }^{35}$ See Owen Hannaway, "Laboratory Design and the Aim of Science: Andreas Libavius versus Tycho Brahe,” Isis, 77 (1986), 585-610. 
Nonetheless, good instruments alone could not guarantee the best results. Ptolemy, for example, had used instruments built at the expense of the "royal Egyptians" and still got results that Tycho sometimes found wanting in precision (VII, 259). A prerequisite for reaching good results even with good instruments was a commitment to observation itself which Copernicus seemed to lack. Tycho's discussion of the lunar model provides a good example of his combined admiration and disappointment. On the one hand Tycho believed that Copernicus was both "correct and ingenious to hypothesize that the revolutions of the moon around the earth happen in a concentric circle with two epicycles" and suggested to Peucer that the superior planets should be modelled in the same way (VII, 136). On the other hand Tycho expressed his misgivings to Hagecius in 1595. Although more elegant and probable than Ptolemy's model, Copernicus's theory was not sufficient to save the phenomena:

At the new and full moons and both quadratures he obtains in any case a position such that he does not even there explain all things with the requisite precision. But in the four places which are intermediate to these, he does not at all save the appearances, unless we count for nothing the loss of one half degree when the moon is near the mean elongations of the bigger epicycle and of almost one whole degree when it is near apogee or perigee. (VII, 370)

In order to account for his observations Tycho introduced the third inequality of the moon, or variation. ${ }^{36}$ The problem, as Tycho explained in 1599 to Herwart von Hohenburg, was that Copernicus, following the practice of earlier astronomers, had used only three eclipse observations, "which do not suffice to explain the first inequality of the moon, to say nothing of the other more complicated one." Establishing new standards for derivation, Tycho insisted rather that it was "necessary to have more very accurate observations taken in different places of the eccentric or the major epicycle" (VIII, 161).

Although Tycho recognized that Copernicus had simply followed a long-standing practice in deriving the lunar inequalities from only three observations, he was especially critical of this tendency of his contemporaries, and of Copernicus in particular, to rely on the authority of received values rather than on their own observations. When determining the maximal lunar latitude for example, Tycho obtained a value of $5^{\circ} 15^{\prime}$, rather than the $5^{\circ}$ that Ptolemy and modern astronomers after him had thought to be correct. As Victor Thoren has argued, this reassessment played an important role in leading Tycho to his new theory of the lunar latitude and oscillation. ${ }^{37}$ But when he first suggested the new parameter,

$36: \rightarrow$ Victor E. Thoren, “Tycho Brahe's Discovery of the Variation," Centaurus, 12 (1967), 151-66.

${ }^{37}$ Victor E. Thoren, “An Early Instance of Deductive Discovery: Tycho Brahe's Lunar Theory," Isis, 58 (1967), 19-36. 
his friend and correspondent Henry Brucaeus objected that the traditional value must be the more accurate. In his reply in 1588 Tycho lashed out against Brucaeus for his excessive deference to authority, but Copernicus once again bore the brunt of his criticism:

The authority of Regiomontanus, Copernicus, Werner, and others (whoever they are) does not move me on this issue, since the restoration of astronomy must derive not from the authority of men, but from reliable observations and demonstrations based on them.... Copernicus accepted without change the maximal latitude of the moon from Ptolemy and did not try to see for himself in the sky whether it was the case or not; Copernicus used as an excuse the fact that fate had not given him the same opportunity to see for himself that Ptolemy had, because the obstacles of the lunar parallaxes at his greater polar elevation could not be easily avoided as they could in Alexandria, which Copernicus makes clear in his own words in De revolutionibus book 4, chapter 15. (VII, 152-53) ${ }^{38}$

In this instance Tycho agreed with Copernicus's assessment of Ptolemy's superior observational conditions and results. Tycho did not replace Ptolemy's value of the maximal lunar latitude with his own, but rather used it as "correct in his time" and concluded from the difference between his own observations and Ptolemy's values that there had been a secular shift in the maximal latitude of the moon similar to that in the angle of the obliquity of the ecliptic (VII, 153). Although Tycho later rejected this particular interpretation and concluded that the important difference between "his and Ptolemy's determinations was the phase of the moon rather than the era of observation," 39 he maintained that the deviation of Ptolemy's value from his own "by a quarter of a degree was not the result of a fault of instrumentation or observation" (VII, 153). Copernicus's real mistake, then, was not so much that he trusted Ptolemy's value but rather that he did not even try to make his own observations. Tycho had little sympathy for Copernicus's argument that his northerly location created insurmountable obstacles for observing the moon. Despite his own far worse conditions, as Tycho reminded Kepler in a letter in 1599, he had obtained reliable results from even more difficult observations: "Though it [Mercury] rarely passes beyond the sun's rays [which make it invisible] and the sphere is more inclined in our Denmark than in Frauenburg in Prussia where Copernicus lived, and the sea around our island creates more fogs than the Vistula: nonetheless we have frequently made accurate

${ }^{38}$ The reference is to De revolutionibus, book IV, chapter 15: "Because of the obstacle of the lunar parallaxes, fortune did not give us the opportunity to test, as it gave Ptolemy, that the greatest latitude of the moon, conforming to the angle of intersection of its orb and the ecliptic, is $5^{\circ}$." Copernicus, f. $117 \mathrm{r}$.

${ }^{39}$ Victor E. Thoren, "Tycho and Kepler on the Lunar Theory," Publications of the Astronomical Society of the Pacific, 114 (1967), 484. 
observations even of Mercury, a most difficult planet to follow" (VIII, 208). ${ }^{40}$

Tycho's own attitude toward the observations of the ancients is interesting and complex. On the one hand he clearly appreciated Ptolemy's skill as an observational astronomer, as in the case of the lunar latitude. Tycho also expressed great respect for the observations of Hipparchus (VII, 373-74; VIII, 104). On the other hand, however, Tycho was also willing to consider ancient observations erroneous by a certain margin when they seemed unreasonable. For example, when Tycho planned an expedition to Alexandria to measure the polar elevation there, he told Magini in a letter dated 1590 that he wanted to show that the "elevation of the pole had not noticeably changed over the intervening centuries, unless perhaps Ptolemy erred by a very few minutes" (VII, 298). Intent on refuting the suggestion by Domenicus Maria of Novara that latitudes had changed over the centuries and that the pole had shifted toward the zenith since Ptolemy's time, Tycho would have concluded that any difference of "a very few minutes" between Ptolemy's and his own observations reflected an error on Ptolemy's part rather than a secular shift. In fact the expedition never took place. ${ }^{41}$

The estimation of the rate of the precession of the equinoxes offers another example of Tycho's attitudes toward ancient observations since it relies crucially on earlier results. Copernicus had proceeded with total confidence in the accuracy of all available observations and, when comparing them with his own, arrived at a figure for the rate of precession which was both faster than Ptolemy's and itself irregular. It was to account for this irregularity that Copernicus introduced the libration of the third motion of the earth, which, of all the motions that Copernicus had attributed to the earth, Tycho had always found particularly useless (otiosus, VIII, 45).

In 1595 in a discussion of the calendar with Isaac Pontanus, royal historian of Denmark, Tycho justified his determination of the length of the year over the past few centuries from its length in the last hundred years, on the grounds that the length of the year does not change with the precession of the equinoxes as quickly as Copernicus had claimed. Tycho reveals here how he established this fact to his satisfaction. Unlike the "lax and credulous" Copernicus, Tycho compared his results with

${ }^{40}$ Tycho is referring to Copernicus's complaints in De revolutionibus, book V, chapter 30, on Mercury: "Of course the ancients showed us this way of examining the path of this star [Mercury], but they enjoyed a more serene sky, where no doubt the Nile, as they say, does not exhale vapors like the Vistula where we are. Nature has denied us this advantage since we live in a more rigorous climate where calm weather is rarer and in addition it is more rarely possible to see Mercury because of the great inclination of the sphere." Copernicus, f. 369 r.

${ }^{41}$ William Norlind, “Tycho Brahe et ses rapports avec l'Italie,” Scientia, 49 (1955), 51. 
only the most trustworthy of those of the ancients and as a consequence found precession to be smaller and more regular than Copernicus had:

Although the quantity of the equinoctial or solar year that I use for these centuries was derived only from an epoch one hundred years ago, from the observations of Regiomontanus and his student Walther, deliberately, so that I avoided the labyrinths of inequality which Copernicus and others introduced (as I see it) because of their excessive credulity and laxity: nonetheless if a proper comparison is made with the observations of centuries earlier, especially with those which are deserving of our trust beyond a doubt (such as I judge those of Hipparchus above all others, who most diligently attended to the appearances of both the sun and the moon), the annual quantity defined by us falls short by very few, possibly 5 or 6 , seconds and thus in no way affects the determination of the years. But my observations when applied to the best of the ancient ones show that the disparity in the quantity of the year and the motion of the fixed stars is not as great nor of such great moment as astronomers think. (VII, 373-74)

The key to Tycho's approach to the precession was a circumspect attitude toward ancient parameters rather than the excessively confident trust that Tycho attributed in Copernicus not only to credulity but also to a certain "laxity," a reluctance to make countless diligent observations as Tycho had.

Tycho was equally distressed by Copernicus's planetary positions. He found "no small deviation from the measure of the sky in the latitudes" of Mercury and the three superior planets (VIII, 161). As for Venus, Tycho told Kepler, its eccentricity was much smaller than Ptolemy or Copernicus had thought and its apogee was not fixed with respect to the stars as Copernicus had believed, but now had already reached the beginning of Cancer (VIII, 45). Although more conciliatory in the early stages of his observational project, Tycho still reported errors by Copernicus for each of the superior planets in a 1590 letter to Hagecius:

The hypothesis of Copernicus is nonetheless closer [than Ptolemy's] to the measure of the heavens, except that in Jupiter it deviates sometimes by more than one degree, and in Saturn up to one half of a degree. I have not found until now that Copernicus committed a greater discrepancy from the sky in the two slowest planets, though for Mars the discrepancy reaches sometimes three degrees, or even a little more... Our observations, compared with the ancient ones will provide some day, God willing, a more exact correspondence with the celestial appearances of the planets. (VII, 269)

Five years later, writing to Hagecius again, Tycho sounded more exasperated:

In constituting the apogees of the other planets (not to speak of the eccentricities, which he derived too confidently from Ptolemy) the great Copernicus, who is never enough praised, erred in no small way.... In the numbers of Copernicus the apogee of Mars is more than five degrees beyond where the measure of the 
heavens demands, and the eccentricity, which he made smaller than the Ptolemaic value (perhaps so that he could with more probability support his own speculation about the motion of the earth and the changed eccentricity of the sun) is so far from being smaller that it is necessary to make the same rather barely larger (by a very few minutes though) only to satisfy the phenomena of Mars in all respects. (VII, 370)

Tycho concluded the tirade with an explicit statement of the argument underlying most of his parametric complaints: "And on the basis of this experimentum alone, the position of Copernicus on the motion of the earth and the immobility of the sun is weakened" (VII, 370) ${ }^{42}$ In a similar way Tycho argued with Rothmann that "the fact that the eccentricity of Mars by no means corresponds to what the Copernican theories require is a strong argument for their weakness" (VI, 336). Tycho concluded with the implication that it was Copernicus's faulty parameters which had led him to doubt the veracity of the heliocentric system: "the fact that his hypotheses are less correct [than Ptolemy's] causes me no small hesitation" (VI, 336).

Tycho's litany of criticisms of Copernicus's parameters and observations is in part a contribution to his ongoing argument against the Copernican system as a whole and especially its heliocentrism. Although Tycho would no doubt have recognized that each particular discrepancy could be resolved without affecting the hypothesis of the motion of the earth, to tarnish the Copernican system even if only by association by pointing to its numerous empirical flaws was, Tycho hoped, to make the Tychonic system more appealing. Given the otherwise wide acclaim of sixteenthcentury astronomers for the Copernican parameters, to which Tycho himself had contributed as a young lecturer, these specifically parametric criticisms are unique and proved to have a more enduring impact than Tycho's system itself. ${ }^{43}$

\section{Tycho's legacy}

In addition to undermining the Copernican system in a loose way, Tycho's critique of Copernicus's parameters served as the background against which Tycho defined his own, new standards of astronomical practice. Tycho would certainly not have attacked Copernicus's parameters had he not already been particularly sensitive, for whatever combination of factors, to numerical accuracy. Nonetheless it is probable that Tycho's constantly renewed awareness of Copernicus's shortcomings con-

${ }^{42}$ Experimentum here denotes a refined observation to be used as the basis for a choice between theories. For more on the use of the term in this period see Charles B. Schmitt, "Experience and Experiment: A Comparison of Zabarella's View with Galileo's in de Motu," Studies in the Renaissance, 16 (1969), 80-138.

${ }^{43}: \rightarrow$ C. Doris Hellman, "Was Tycho Brahe as Influential as He Thought?" British Journal for the History of Science, 1 (1963), 295-324. 
tributed to a more explicit realization and discussion of his own suggestions for "restoring" astronomy.

Thus, for example, Tycho called for a closer consideration of the effects of refraction. Refraction had probably distorted Copernicus's estimate of the polar elevation of Frauenburg, and, as Tycho commented in a number of places, refraction also caused Copernicus to underestimate the obliquity of the ecliptic by three or four minutes (VII, 280-81; VIII, 197-98). Although Tycho himself believed that refraction was caused by atmospheric vapors that disappeared above a certain altitude, ${ }^{44}$ for all observations at an altitude of less than $45^{\circ}$ at least Tycho insisted that refraction be taken into account. He drew up tables of refraction to that end which, albeit unpublished, circulated as an appendix to his catalogue of 1000 stars to Tycho's potential patrons. ${ }^{45}$

Tycho also laid down clear rules for the construction of accurate instruments - to be made only of metal and of sufficient size to bear graduations down to the minute. Tycho was proud to have devised a method for "subdividing degrees of arc through the use of transversal points and of tiny slit sights on alidades," so proud in fact that he accused Rothmann of stealing it from him without acknowledgment. ${ }^{46}$ As well as a bid for patronage, Tycho's description of his instruments and installation at Uraniborg in his Astronomiae instauratae mechanica constituted a normative depiction of how astronomy should be practised, and included detailed specifications of his different instruments, complete with illustrations.

Tycho's criticisms of Copernicus especially emphasized what could be called his "astronomical method." Tycho's most common criticism of Copernicus's method was that he relied excessively and too confidently on received parameters, notably Ptolemy's. Tycho insisted rather that the sky was the only guide to be followed. Tycho himself, however, was guilty of the same offense, although he certainly would never have admitted it. Tycho accepted without recomputation the traditional value for the solar parallax for example. Although Tycho's final verdict on the relative positions of Mars and the sun favored the Copernican and Tychonic systems, it rested less on solid empirical ground-Tycho claimed to have found a greater parallax for Mars than for the sun while using an excessively large value for the latter-than on Tycho's own cosmological commitments. But Tycho's great reputation for observational accuracy, which in this case was hardly warranted, turned his "test" from the parallax of Mars into a powerful argument in favor of heliocentrism; long after his death

${ }^{44}$ Dreyer, Tycho Brahe, 336.

${ }^{45}$ Ibid., 265.

${ }^{46}$ Bruce T. Moran, "Christoph Rothmann, the Copernican Theory and Institutional and Technical Influences on the Criticism of Aristotelian Cosmology," Sixteenth-Century Journal, 13 (1982), 90-97. 
his "observation" of the greater parallax of Mars was cited with unquestioning approval. ${ }^{47}$

Where Tycho really did differ from Copernicus was not so much in his rejection of authority, which was sometimes more pretense than reality, but rather in his insistence on the difficulty of observational astronomy. Tycho had attacked Copernicus for relying on too few observations for his derivations. Three eclipse observations alone could not establish the first lunar inequality; furthermore, as Tycho warned Magini in 1598, "neither do three observations suffice to explain the apogees and eccentricities [of the planets] as astronomers in imitation of Ptolemy and Copernicus have in vain believed until now" (VIII, 121). Tycho on the contrary expressed his dissatisfaction, in a letter to Kepler in 1598, with the number of observations that even he had accumulated by the end of his years in Hveen: "if truer measurements of the eccentrities of each planet were available, such as those that I have at my disposal gathered over many years, they could allow a more accurate judgment in these matters" (VIII, 44). He concluded to Maestlin later that year that too little was known of the motions of the planets to support a hypothesis: "the double inequalities of the planets, which [astronomers] explain by a double eccentric or epicycle, are not yet well enough unravelled" (VIII, 53).

Tycho was clearly willing to be patient. He had painstakingly observed Mercury whenever possible despite the difficult conditions at Uraniborg. He noted in his preface to his astronomical letters how slow his work had been: if Mercury was notoriously hard to see, "even observations of the three slow-moving planets, which [astronomers] call superior, sufficient to restore their motions appropriately, require no small amount of time" (VI, 20). As a consequence, Tycho recognized that some parts of astronomy would perhaps never be completed. The motion of the fixed stars due to the precession of the equinoxes was a particularly difficult topic since "it is not reasonable that the inequality be at all noticeable in the stars in the life of one man" and Tycho conceded to the Landgrave of Hesse in 1587: "I believe that an exact knowledge of the apparent motion of the eighth sphere is hardly attainable for any mortal" (VI, 73).

Finally, Tycho stressed the need to verify observations and derivations. Especially for observations of the fixed stars "Ptolemy did not use in verifying them the diligence and precision which were necessary, and still less did Copernicus" (VII, 268). Although Dreyer was "disappointed" with Tycho's own verifications and care in determining the positions of the stars outside the ecliptic in his star catalogues, Tycho is noted for his "practice of using redundant data and admitting scatter into his results." 48

${ }^{47}$ Schofield, 69.

${ }^{48}$ J. L. E. Dreyer, "Tycho Brahe's Catalogue of Stars," Observatory, 40 (1917), 233. Victor E. Thoren, "The Comet of 1577 and Tycho Brahe's System of the World," Archives Internationales d'Histoire des Sciences, 29 (1979), 55. 
Tycho also suspected that in determining the eccentricity and apogee of Mars, "since in both cases the error was perceptible enough, Copernicus had arranged his results to fit his assumptions rather than testing the latter sufficiently against indubitable observations" (VII, 292-93).

Tycho's novel appreciation of the arduous and slow process of collecting and then using good observations may have prevented him from ever presenting his own system in detail. As Thoren has noted, however, the models which Tycho did complete, for the motions of the moon and the sun for example, constitute examples of empirical derivation of the highest caliber. ${ }^{49}$ No doubt Tycho's critique of Copernicus grew out of his commonplace rejection of heliocentrism on physical, scriptural, and cosmological grounds, and was fueled in part by his self-interest in promoting his own geoheliocentric system; nonetheless in his unique attack on Copernicus's observational practice and derivation of parameters, Tycho became aware of the shortcomings of his predecessors and formulated explicitly his own requirements for the restoration of astronomy. With a keen sense of the commitment and constant effort required of whomever would restore the discipline, Tycho called for better instruments, more careful and diligent observations and greater prudence and patience in a directly empirical derivation of models. Drawing on this refined program of astronomical practice, Kepler in turn would refine the notion of astronomical theory, its nature, development, and sources. ${ }^{50}$

\section{Princeton University.}

${ }^{49}$ Victor E. Thoren, "Tycho and Kepler on the Lunar Theory," 483.

${ }^{50}$ See for example Judith V. Field, Kepler's Geometrical Cosmology (Chicago, 1988) and Bruce Stephenson, Kepler's Physical Astronomy (New York, 1987). 